\title{
Large ovarian mucinous cystadenoma in premenarchal girl - a case report
}

\author{
Pramod S, Katragadda Satya Vani \\ Correspondence: Pramod S, Assistant Professor, Department of Paediatric Surgery, \\ Kempegowda Institute of Medical Sciences and Research Institute, Bangalore, Karnataka, \\ India; Email: pramodbmc76@gmail.com
}

Distributed under Creative Commons Attribution-Share Alike 4.0 International.

\begin{abstract}
Most common ovarian mass in children is benign functional cyst. Epithelial tumors account for $8-10 \%$ of ovarian tumors. Most common epithelial tumor is cystadenoma. Mucinous cystadenoma occurs in $3^{\text {rd }}-6^{\text {th }}$ decade of life. We report a case of 10 years old premenarchal girl presenting with abdominal distension and discomfort. On examination the entire abdomen was occupied by a firm mass. CT imaging showed a large multiloculated cystic lesion arising from the right ovary. The child underwent right salphingo-oophrectomy. The biopsy of the mass was suggestive of benign mucinous cystadenoma. The child was on regular follow up. After 1 year of follow up child is doing well.
\end{abstract}

Keywords: Mucinous cystadenoma, abdominal distension, premenarchal.

Ovarian tumors are rare in children younger than 15 years of age ${ }^{1}$. Their incidence is estimated to be 2.6 cases per $1,00,000$ girls $^{1}$. Ovarian tumors account for $1-1.5 \%$ of all the childhood malignancies ${ }^{2}, 3$. In children most common ovarian masses are non neoplastic lesion such as benign functional cyst. Epithelial tumors of ovary account for $8-10 \%$ of ovarian tumors. Epithelial tumors are histologically classified as serous and mucinous. Most common benign epithelial tumor is cystadenoma of which $75 \%$ are serous and $25 \%$ are mucinous cystadenoma ${ }^{4,5}$. Mucinous cystadenoma are benign ovarian epithelial neoplasms that occur in $3^{\text {rd }}-6^{\text {th }}$ decade of life ${ }^{2}$. In literature less than 20 cases have been reported so far in premenarchal age group.

These tumors usually are asymptomatic; grow slowly to a large size before they are diagnosed. In some cases large cyst can causes uretric compression and renal insufficiency. Treatment includes ipsilateral salphingooophrectomy. Here we present a case of 10 years old girl with large mucinous cystadenoma.

\section{Case report}

A 10 years old girl presented with vague abdominal pain since 5 months with fullness in the lower abdomen. Child had no history of vomiting, urinary or bowel disturbance. General condition of the child was normal. Abdominal examination revealed a mass extending from pelvis to the epigastrium (Figure 1). The mass was firm in consistency, intraperitoneal and the lower margins were dipping into the pelvis. An ultrasonography of the abdomen showed a large multiloculated swelling extending from pelvis into the epigastrium. The origin of the mass could not be identified. CT scan revealed a large

Received: $15^{\text {th }}$ January 2018. Accepted: $11^{\text {th }}$ June 2018.

Pramod S, Vani KS. Large ovarian mucinous cystadenoma in premenarchal girl: a case report. The New Indian Journal of OBGYN. 2018; 5(1): 57-59. 
multiloculated cystic swelling measuring about $13 \times 12 \mathrm{~cm}$ arising from right ovary (Figure 2). Tumor markers

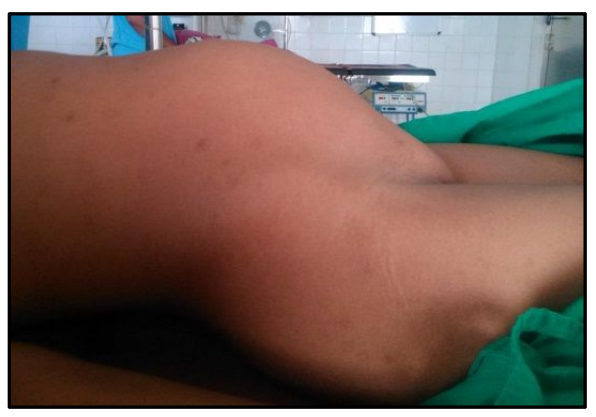

Figure 1: Fullness of abdomen

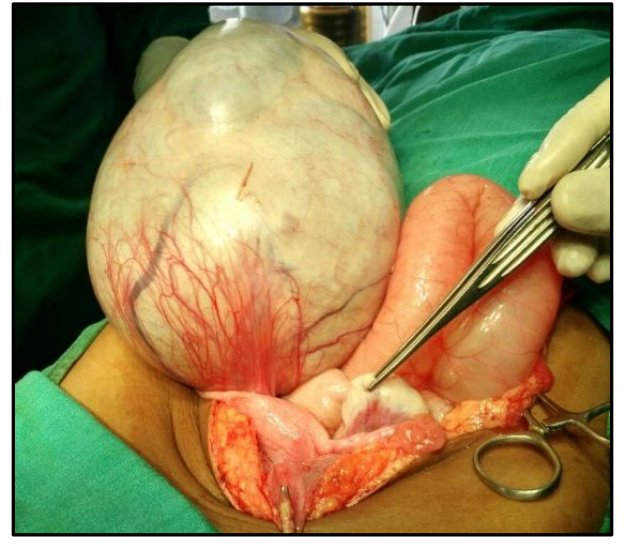

Figure 3: Intraoperative picture
CA125, CA 19-9, beta HCG and alpha feto protein were within normal limits. The routine blood investigations were within normal limits. Renal and liver function tests were also normal.

Child underwent laparotomy. The entire abdomen was filled with a smooth walled cystic mass. The right ovary

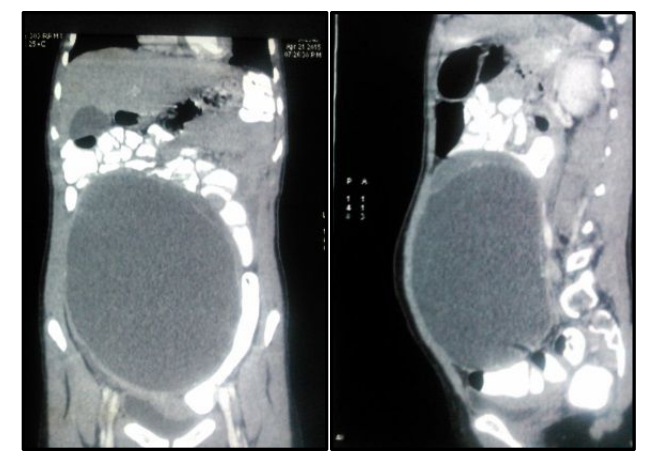

Figure 2: CT image showing multiloculated cyst

was completely replaced by the mass (Figure 3 ). The left ovary was normal in size and shape for the age. The child underwent right salphingo-oophrectomy. Rest of the abdomen was normal. The child was started on feeds on post operative day 2. Postoperative recovery was uneventful and child was discharged on post operative day 5. Histopathology was suggestive of mucinous cystadenoma of right ovary. Child was on regular follow up since 1 year and recent follow up scan done one year after surgery shows normal left ovary.

\section{Discussion}

Ovarian tumors and primary ovarian cyst are uncommon in children. One third of these masses are non neoplastic. In adolescence the differential diagnosis of ovarian masses include functional cyst, benign or malignant ovarian neoplasm, ovarian torsion and ovarian involvement with leukemia, lymphoma or metastatic disease ${ }^{2,6}$. Epithelial tumors account for $8-10 \%$ of neoplastic tumors. Epithelial ovarian tumors in children are commonly benign cystadenoma of which $75 \%$ are serous and remaining $25 \%$ are mucinous ${ }^{4,5}$. Very few cases of benign mucinous cystadenoma have been reported in pediatric age group. About 19 cases of benign mucinous cystadenoma have been reported in pediatric age group ${ }^{7}$.

These tumors are usually slow growing with non specific symptoms. Hence diagnosis is delayed. Usual presentation is vague abdominal pain, discomfort and distension. In our case also the child had vague symptoms with abdominal distension since 5 months. On abdominal examination the mass was occupying the entire abdomen. This finding is compatible with previous reports in literature ${ }^{7}$. Usually the left ovary has predilection for these tumors ${ }^{7}$. But in our case the right ovary was involved.

The first modality of investigation includes ultrasonography of the abdomen and pelvis to identify the origin of the mass. In doubtful cases a CT or MRI may be required. In our child a CT was required to identify the organ from where mass had arisen. Pre operative tumor 
The New Indian Journal of OBGYN. 2018 (July-December); 5(1)

markers which were estimated includes CA 125, CA 19-9, Alfa Feto Protein and Beta HCG. CA 125 is a high molecular weight glycoprotein expressed by epithelial tumors. CA19-9 is an antigen secreted by mucinous tumors. These markers indicate complete resection and relapse. In the present case all the above tumor markers were within normal limits.

Treatment is usually surgical. Treatment options for benign tumors include cystectomy, ipsilateral oophorectomy or salpingo-oophorectomy. In cases of benign mucinous cystadenoma unilateral salphingo oopherectomy is sufficient ${ }^{8}$. The opposite ovary is inspected at the time of surgery. If it is normal, biopsy is not necessary. Biopsy may lead to adhesion formation and jeopardize future fertility ${ }^{9}$. The present child underwent right salphingo-oophrectomy. No biopsy of the left ovary was taken as the ovary was grossly normal.

Recurrence is not so rare. Intraoperative cyst rupture and cystectomy instead of adnexectomy have emerged as risk factors for recurrence ${ }^{10}$. Hence the tumor should be removed carefully and completely. The present child is on regular follow up. Child is symptomatically normal and Ultrasonography at 1 year post surgery is normal.

\section{Conclusion}

Though germ cell tumors are common in children, epithelial tumors must also be considered. Mucinous cystadenoma present as large abdomino pelvic mass with vague symptoms. Surgery is treatment of choice.

\section{Conflict of interest: None. Disclaimer: Nil.}

\section{References}

1.Lindfords O. Primary ovarian neoplasms in infants and children: a study of 81 cases diagnosed in Finland and Sweden. Ann Chir Gynaecol Fenn Suppl. 1971; 177: 1- 66.
2.Brown MF, Hebra A, McGeechin K, Ross AJ 3rd. . Ovarian masses in children: a review of 91 cases of malignant and benign masses. J Pediatr Surg. 1993; 28: 93033 .

3.Freud E, Golinsky D, Steinberg RM, Blumenfeld A, Yaniv I, Zer M. Ovarian masses in children. Clin Pediatr (Phila). 1999; 38: 573-77.

4.Parmentier B, Vaz E, Chabaud-Williamson M, et al. Mucinous cystadenoma arising 3 years after ovarian-sparing surgery for mature teratoma in child. J Pediatr Surg. 2010; 45: 9-12.

5.Karaman A, Azili MN, Boduroglu EC, et al. A huge ovarian mucinous cystadenoma in a 14-year-old premenarchal girl: review on ovarian mucinous tumor in premenarchal girls. J Pediatr Adolesc Gynecol. 2008; 21: 414.

6. Yazici M, Etensel B, Guursoy H, Erkus M. Mucinous cystadenoma a rare abdominal mass in childhood. EUR J Pediatr Surg. 2002; 12: 330-32.

7.Sri Paran T, Mortell A, Devaney D, Pinter A, Puri P. Mucinous cystadenoma of ovary in perimenarchal girls. Pediatr Surg Int. 2006; 22: 224-27.

8.Flotho C, Ruckauer K, Duffner U, Bergstasser E, Bohm N, Neimeyer CM. Mucinous cystadenoma of the ovary in a 15 year old girl. J Pediatr Surg. 2001; 36: 1-3.

9.Lazar EL. Evaluation and management of pediatric solid ovarian tumors. Semin Pediatr Surg. 1998; 7: 29-34.

10.Ben-Ami I, Smorgick N, Tovbin J, et al. Does intraoperative spillage of benign ovarian mucinous cystadenoma increase its recurrence rate? Am J Obstet Gynecol, 2010; 202(2): 142e1-5

Pramod $\mathrm{S}^{1}$, Katragadda Satya Vani ${ }^{2}$

${ }^{1}$ Assistant Professor, Department of Paediatric Surgery; ${ }^{2}$ Resident, Department of Surgery, Kempegowda institute of medical Sciences and Research Institute, Bangalore. 